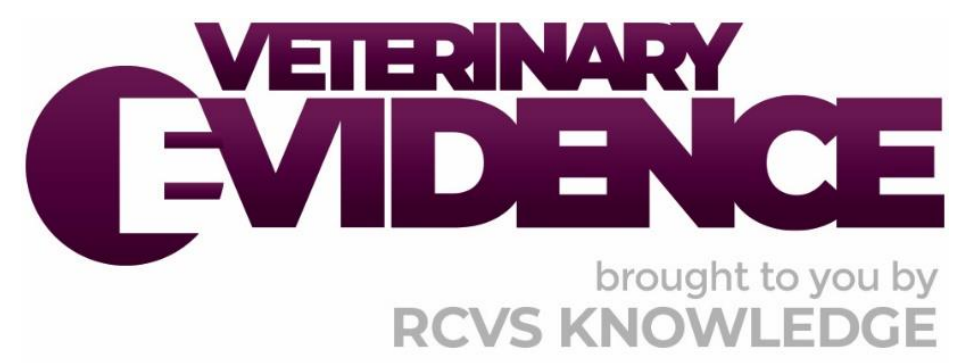

\title{
In dogs with uncomplicated corneal ulcers, do antibacterial eye drops reduce the risk of infection?
}

\author{
A Knowledge Summary by
}

Sery Johnson $\mathrm{BS}^{1^{*}}$

Wanda J Gordon-Evans DVM PhD DACVS DACVSMR ${ }^{1}$

\footnotetext{
${ }^{1}$ University of Minnesota College of Veterinary Medicine, 1365 Gortner Ave, St Paul, MN 55108, USA

* Corresponding Author (joh10898@umn.edu)
}

ISSN: 2396-9776

Published: 17 Nov 2021

in: The Veterinary Evidence journal Vol 6, Issue 4

DOI: https://doi.org/10.18849/ve.v6i4.389

Reviewed by: Kazuya Oikawa (BVSc PhD) and Constance Neville White (DVM PhD)

Next Review Date: 07 Dec 2022 


\section{KNOWLEDGE SUMMARY}

\section{PICO question}

In dogs with uncomplicated corneal ulcers does treatment with prophylactic antibacterial eye drops reduce the risk of secondary infection when compared to no treatment with prophylactic antibacterial eye drops?

\section{Clinical bottom line}

\section{Category of research question}

Treatment

The number and type of study designs reviewed

Zero

\section{Strength of evidence}

Zero

\section{Outcomes reported}

None

\section{Conclusion}

There were no published papers found to address the PICO

\section{How to apply this evidence in practice}

The application of evidence into practice should take into account multiple factors, not limited to: individual clinical expertise, patient's circumstances and owners' values, country, location or clinic where you work, the individual case in front of you, the availability of therapies and resources.

Knowledge Summaries are a resource to help reinforce or inform decision making. They do not override the responsibility or judgement of the practitioner to do what is best for the animal in their care.

\section{Clinical Scenario}

You are presented with a 4 year old, female spayed dog of mixed breed with an acute onset of epiphora and blepharospasm of the right eye. Ocular exam and fluorescein staining reveal a superficial corneal ulcer, which has not received any treatment prior to diagnosis. The dog's owner has already spent more money than she would like just for the exam and wants to know whether the recommended antibacterial drops are necessary.

\section{The evidence}

There was no peer-reviewed evidence that met the inclusion criteria to summarise.

\section{Appraisal, application and reflection}

In dogs with uncomplicated corneal ulcers, the administration of prophylactic topical ophthalmic antibacterials is well documented and recommended in textbooks on veterinary ophthalmology as the standard of care (Maggs et al., 2018); for the purpose of this Knowledge Summary, an uncomplicated corneal ulcer was defined as a new onset superficial corneal ulcer. Despite this recommendation, there have been no studies to demonstrate a significant difference in infection rates in affected dogs receiving prophylactic topical ophthalmic antibacterials compared to dogs that do not. However, the potential negative impacts of not 
treating uncomplicated corneal ulcers with topical ophthalmic antibacterials could be significant, possibly resulting in secondary ocular infections, melting deep corneal ulcers, and may eventually lead to loss of vision or loss of the eye. Therefore, unless robust evidence is established to refute the current dogma, it is recommended that practitioners continue to uphold the current standard of care.

\section{Methodology Section}

\begin{tabular}{|r|l|}
\hline \multicolumn{2}{|l|}{ Search Strategy } \\
\hline Databases searched and dates \\
covered:
\end{tabular} $\begin{aligned} & \text { CAB Abstracts on OVID Platform; 1973-2020 } \\
& \text { PubMed on NCBI Platform; 1950-2020 }\end{aligned}$

\section{Exclusion / Inclusion Criteria}

Exclusion: Articles not available in English, clinical review articles, book chapters, articles not available for review

Inclusion: Articles relevant to the PICO (involving uncomplicated corneal ulcers that were treated to resolution)

\begin{tabular}{|c|c|c|c|c|c|}
\hline \multicolumn{6}{|c|}{ Search Outcome } \\
\hline Database & $\begin{array}{c}\text { Number of } \\
\text { results }\end{array}$ & $\begin{array}{l}\text { Excluded - } \\
\text { Did not } \\
\text { address the } \\
\text { PICO }\end{array}$ & $\begin{array}{l}\text { Excluded - } \\
\text { Not English } \\
\text { language }\end{array}$ & $\begin{array}{l}\text { Excluded - } \\
\text { Non-canine }\end{array}$ & $\begin{array}{c}\text { Total relevant } \\
\text { papers }\end{array}$ \\
\hline CAB Abs & 331 & 223 & 97 & 11 & 0 \\
\hline PubMed & 391 & 335 & 33 & 23 & 0 \\
\hline \multicolumn{5}{|c|}{ Total relevant papers when duplicates removed } & 0 \\
\hline
\end{tabular}

\section{CONFLICT OF INTEREST}

The authors declare no conflict of interest.

\section{REFERENCES}

1. Maggs, D. J., Miller, P. E. \& Ofri, R. (2018). Slatter's Fundamentals of Veterinary Ophthalmology (6th ed.). Elsevier. 


\section{EVIIDEFeE

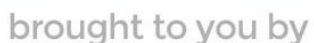 \\ RCVS KNOWLEDGE}

\section{Intellectual Property Rights}

Authors of Knowledge Summaries submitted to RCVS Knowledge for publication will retain copyright in their work, and will be required to grant RCVS Knowledge a non-exclusive license of the rights of copyright in the materials including but not limited to the right to publish, re-

publish, transmit, sell, distribute and otherwise use the materials in all languages and all media throughout the world, and to license or permit others to do so.

\section{Disclaimer}

Knowledge Summaries are a peer-reviewed article type which aims to answer a clinical question based on the best available current evidence. It does not override the responsibility

of the practitioner. Informed decisions should be made by considering such factors as individual clinical expertise and judgement along with patient's circumstances and owners' values. Knowledge Summaries are a resource to help inform and any opinions expressed within the Knowledge Summaries are the author's own and do not necessarily reflect the view of the RCVS Knowledge. Authors are responsible for the accuracy of the content. While the

Editor and Publisher believe that all content herein are in accord with current recommendations and practice at the time of publication, they accept no legal responsibility

for any errors or omissions, and make no warranty, express or implied, with respect to material contained within.

For further information please refer to our Terms of Use.

RCVS Knowledge is the independent charity associated with the Royal College of Veterinary Surgeons (RCVS). Our ambition is to become a global intermediary for evidence based veterinary knowledge by providing access to information that is of immediate value to practicing veterinary professionals and directly contributes to evidence based clinical decision-making.

https://www.veterinaryevidence.org/

RCVS Knowledge is a registered Charity No. 230886.

Registered as a Company limited by guarantee in England and Wales No. 598443.

Registered Office: Belgravia House, 62-64 Horseferry Road, London SW1P 2AF

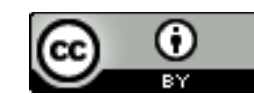

This work is licensed under a Creative Commons Attribution 4.0 International License 